Antônio Ignácio de Loyola Filho,,II

Érico Castro-Costa'

Josélia Oliveira Araújo Firmo'

Sérgio Viana Peixotot, ${ }^{1,11}$
Núcleo de Estudos em Saúde Pública e Envelhecimento. Centro de Pesquisas René Rachou. Fundação Oswaldo Cruz. Belo Horizonte, MG, Brasil

Departamento de Enfermagem Aplicada. Escola de Enfermagem. Universidade Federal de Minas Gerais. Belo Horizonte, MG, Brasil

Correspondence:

Antônio Ignácio de Loyola Filho

Fundação Oswaldo Cruz

Av. Augusto de Lima, 1715 Sala 608

30190-002 Belo Horizonte, MG, Brasil

E-mail: aloy@cpqrr.fiocruz.br

Received: 2/23/2014

Approved: $7 / 28 / 2014$

Article available from: www.scielo.br/rsp

\section{Trends in the use of antidepressants among older adults: Bambuí Project}

\section{Tendências no uso de antidepressivos entre idosos mais velhos: Projeto Bambuí}

\begin{abstract}
OBJECTIVE: To analyze the trends and factors associated with the antidepressant use among older adults.

METHODS: This population-based study evaluated older adults in $1997(\mathrm{n}=351$, baseline $)$ and the survivors at the $15^{\text {th }}$ follow-up year ( $n=462$, in 2012) among the aging cohort of Bambuí. The prevalence of antidepressant use was estimated, and the most commonly used antidepressants each year were identified. Prevalence ratios with $95 \%$ confidence intervals were estimated using Poisson regression with robust variance to investigate differences in the prevalence of use between 1997 and 2012.
\end{abstract}

RESULTS: The overall consumption of antidepressants $(\mathrm{PR}=2.87$, $95 \% \mathrm{CI} 1.94 ; 4.25)$ and of selective serotonin reuptake inhibitors ( $\mathrm{PR}=7.50$, $95 \%$ CI 3.74;15.02) was significantly higher in 2012. However, no significant difference was observed in the use of tricyclic antidepressants between the two cohorts $(\mathrm{PR}=0.89,95 \% \mathrm{CI} 0.49 ; 1.62)$. In the 2012 cohort, antidepressant use was associated with females, increased age, increased income ( $\geq 4$ minimum wages), self-assessment of health as reasonable, and attending $\geq 5$ medical consultations in the last 12 months.

CONCLUSIONS: The increased consumption of antidepressants in the period due to increased use of selective serotonin reuptake inhibitors was consistent with results observed in international studies of different population groups and contexts. The positive correlation observed between antidepressant use and family income may be a warning of possible inequalities in access to mental health services.

DESCRIPTORS: Aged. Antidepressive Agents, therapeutic use. Drug Utilization, trends. Socioeconomic Factors. Pharmacoepidemiology. 


\section{RESUMO}

OBJETIVO: Analisar a tendência e os fatores associados ao uso de antidepressivos por idosos mais velhos.

MÉTODOS: Estudo de base populacional com idosos integrantes da linha base $\left(n=351\right.$, em 1997) e dos sobreviventes no $15^{\circ}$ seguimento $(n=462$, em 2012) da coorte idosa de Bambuí. Estimou-se a prevalência do consumo de antidepressivos e foram identificados os antidepressivos mais consumidos em cada ano. Razões de prevalência com intervalos de confiança de $95 \%$ foram estimadas por meio da regressão de Poisson, com variância robusta, na investigação de diferenças de prevalência no uso do medicamento entre os dois anos.

RESULTADOS: O consumo global de antidepressivo ( $\mathrm{RP}=2,87$; IC95\% 1,94;4,25) e do grupo dos inibidores seletivos da recaptura da serotonina (RP $=7,50$; IC95\% 3,74;15,02) foi significativamente maior em 2012. Entretanto, não foi observada diferença significativa no consumo de antidepressivos tricíclicos entre as duas coortes ( $R P=0,89$; IC95\% 0,49;1,62). $\mathrm{Na}$ coorte recente (2012), o uso de antidepressivos mostrou-se associado ao sexo feminino, à idade e à renda ( $\geq 4$ salários mínimos) mais elevadas, à autoavaliação da saúde como razoável e à realização de cinco ou mais consultas médicas nos últimos 12 meses.

CONCLUSÕES: O crescimento do consumo de antidepressivos no período, devido ao aumento no uso dos inibidores seletivos da recaptura da serotonina, mostrou-se consistente com o observado em estudos internacionais, com diferentes populações e contextos. A associação positiva observada em relação à renda alerta para possível desigualdade no acesso aos serviços de saúde mental.

DESCRITORES: Idoso. Antidepressivos, uso terapêutico. Uso de Medicamentos, tendências. Fatores Socioeconômicos. Farmacoepidemiologia.

\section{INTRODUCTION}

Antidepressants (AD) are considered the treatment of choice in acute manifestations of moderate to severe depression for improvement or complete remission of symptoms. ${ }^{9} \mathrm{AD}$ are also used in the management of other health problems, including anxiety disorders and chronic pain. ${ }^{15}$

International population-based studies have identified growth in $\mathrm{AD}$ use, both in the general adult population $^{2,17}$ and among older adults. ${ }^{8,12}$ This growth is due to greater use of selective serotonin reuptake inhibitors, which are gradually replacing tricyclic $\mathrm{AD}$ as the most commonly used chemical subgroup. ${ }^{2,13,17}$

To date, only one Brazilian study ${ }^{20}$ has evaluated the trends in $\mathrm{AD}$ consumption among different population groups. It was conducted in a mid-sized city in Southern Brazil, and it evaluated the use of psychotropic drugs in the adult population aged $\geq 15$ years between 1994 and
2003. The authors reported a significant increase from $8.4 \%$ to $31.6 \%$ in $\mathrm{AD}$ use. However, this difference was not adjusted for sample characteristics that could be associated with the consumption of AD. Other Brazilian studies have investigated $\mathrm{AD}$ use at the population level in terms of prevalence and associated factors. However, they evaluated the overall adult population. ${ }^{6,10,19}$

The presence of chronic comorbidities is a common condition among older adults, and depression is among the chronic diseases that often affects this population. ${ }^{5}$ Older adults are the main consumers of $\mathrm{AD}^{6,20,23}$ and consumption among older adults is higher than that in their younger counterparts. ${ }^{3}$ Considering the rapid aging of the Brazilian population, the challenges this phenomenon poses to pharmaceutical care, and the limited number of studies on this topic, this study aimed to evaluate the trend and factors associated with $\mathrm{AD}$ use among older adults. 


\section{METHODS}

This study is a substudy of the Bambuí Project, a longitudinal study investigating the incidence and predictors of health outcomes among older adults in a community living situation. Details of the methodology used have been presented in a previous publication. ${ }^{16}$

The aforementioned study ${ }^{16}$ was conducted in the city of Bambuí, located in Southwestern state of Minas Gerais, with 15,000 inhabitants in 1997, when the baseline cohort was evaluated by a census of older adults living in the city. In the present study, the older adults considered eligible to participate were aged between 75 and 89 years who were among the baseline of the 1997 cohort (born between 1908 and 1922), herein designated the 1997 cohort, and the survivors of this same cohort in 2012, herein designated the 2012 cohort, in the same age group (born between 1923 and 1937).

The dependent variable was AD use reported by participants in interviews when the drug label and medical prescription were also examined. The medications were identified and their active principles were classified according to the Anatomical Therapeutic Chemical Index ${ }^{\mathrm{a}}$ (ATC).

The medications listed in ATC under code N06A were considered AD. In addition, AD were classified according to their chemical subgroup (ATC level 4) and chemical substance (ATC level 5).

The independent variables included sociodemographic characteristics, health conditions, and descriptors of the use of health care services. Sociodemographic characteristics included sex, age, education (none, 1-3, and $\geq 4$ full years), marital status (married/consensual union, widowed, divorced/single), family income $(<2.0,2.0-3.9$, and $\geq$ 4.0 minimum wage equivalents), and living status (living alone, not living alone). The minimum wage was equivalent to US\$120.00 in 1997 and US\$333.00 in 2012. The health conditions investigated included the presence of common mental disorders (depression and anxiety), self-assessment of health, number of chronic diseases, and functional disability. The common mental disorders were evaluated using the 12-item version of the General Health Questionnaire (GHQ-12), ${ }^{11}$ and individuals with scores $\geq 5$ points were considered positive. Self-assessment of health was based on the answer to the question: "How would you rate your health?" (very good/good; reasonable; poor). The chronic health conditions evaluated were hypertension, diabetes, Chagas disease, heart attack, and stroke, and they were measured on the basis of the patients' medical diagnostic reports. With regard to functional capacity, older adults were considered functionally disabled if they experienced difficulty or were unable to perform at least one of the following basic activities of daily living without help: getting out of bed, eating, walking from one room to another, and bathing. Hospitalization history, number of medical consultations over the past 12 months, and health insurance coverage were the descriptor variables related to the use of health care services.

Data were collected in the homes using questionnaires administered by the interviewers. Interviewers were recruited from the community, had education superior to 11 years, and were trained by the research team, ensuring consistency in applying the instruments and collecting the data in 1997 and 2012.

The prevalence of AD use (overall and by chemical subgroup) was calculated separately for each birth cohort by dividing the number of older adults reporting $\mathrm{AD}$ consumption by the total number of cohort members. In the evaluation of the chemical subgroups and most commonly used active ingredients, the medication was considered the unit of analysis. Therefore, the ratios were calculated by dividing the total number of $\mathrm{AD}$ in each chemical subgroup or active principle by the total number of $\mathrm{AD}$ reported. The chemical subgroups considered were selective serotonin reuptake inhibitors (SSRI), tricyclic $\mathrm{AD}$ (TCA), and monoamine oxidase inhibitors (MAOI). The Chi-square test was used to compare the two birth cohorts in relation to the variables evaluated. The factors associated with AD use (global) in each birth cohort were evaluated using Poisson regression with robust variance to estimate the prevalence ratios and $95 \%$ confidence intervals. The inclusion of a covariate in the statistical model was not influenced by the results of the univariate analyses. The same analytical strategy was used to test the hypothesis of association between the year of the cohort and AD use (overall and by chemical subgroup). However, to determine the differences in the prevalence of use between the 1997 and the 2012 cohorts, only the variables independently associated with $\mathrm{AD}$ use in at least one of the cohorts were included in the multivariate model. In all analytical steps, a significance level of 5\% was used. Data analysis was performed using Stata ${ }^{\circledR}$ version 10 statistical software (Stata Corp., College Station, USA).

The Bambuí Project was approved by the Research Ethics Committee of the René Rachou Research Center (Opinion 346,329 - CAAE 01082212.7.0000.5091). All participants from both cohorts signed a free and informed consent form.

\section{RESULTS}

The 1997 cohort $(\mathrm{n}=351)$ and the 2012 cohort $(\mathrm{n}=462)$ were similar in age (means of 79.8 and 79.9 years,

a World Health Organization. Collaborating Centre for Drug Statistics Methodology. ATC/DDD Index 2013. Geneva; 2013. Available from: http://www.whocc.no/atc_ddd_index 
respectively), sex (60.1\% and $66.5 \%$ were females, respectively), and marital status (50.4\% and $57.7 \%$ were widowed, respectively). When compared with the 1997 cohort, the 2012 cohort had higher education and income ( $p<0.001$ for both variables), lower prevalence of depressive disorders, less disability for at least one basic activity of daily living, better self-assessment of health $(p<0.001)$, better health insurance coverage $(\mathrm{p}<0.001)$, and higher frequency of medical consultations in the past 12 months $(p=0.014)$, although members of this cohort were hospitalized less during in the same period $(p=0.048)$. The complete characterization of the two cohorts can be observed in Table 1.

AD use increased from $8.3 \%$ in 1997 to $23.6 \%$ in 2012, and this trend was observed in both sexes and in all age groups. In both cohorts, consumption was higher among females and increased with age, except among the older male adults of the 1997 cohort, whose consumption was stable across the age groups (Figure).

With regards to the pharmacological classes, changes in the consumption pattern were observed between the two cohorts; the consumption of TCA prevailed in the 1997 cohort, accounting for $69.0 \%$ of total AD consumption, whereas the consumption of SSRI prevailed in the 2012 cohort, accounting for $68.1 \%$ of total AD consumption. The use of MAOI was observed only in the 1997 cohort and the use of other AD (code N06AX) was restricted to the 2012 cohort. However, in both cohorts, the consumption of these chemical groups was lower than that of TCA and SSRI. Citalopram was the most frequently used active ingredient, corresponding to $31.1 \%$ of total consumption in the 2012 cohort, whereas no active ingredient predominated in the 1997 cohort (data not shown).

In the 2012 cohort, the following factors were positively associated $(p<0.05)$ with AD use after univariate analysis: female sex, age, and family income (among the sociodemographic characteristics), presence of depressive disorders, self-assessment of health as poor (among the health conditions), having two or more medical consultations, and type of health insurance coverage (among the characteristics pertaining to the use of health care services). The following variables were positively associated with $\mathrm{AD}$ use after multivariate analysis: female sex, family income $\geq 4$ minimum wage equivalents, self-assessment of health as reasonable, and having five or more medical consultations in the last 12 months (Table 2). In the 1997 cohort, having five or more medical consultations was the only variable positively associated with $A D$ use using both univariate and multivariate analyses $(\mathrm{OR}=$ 4.41, 95\%CI 1.21;16.1) (data not shown).

Table 3 shows the results of univariate and multivariate analyses for the association between birth cohorts and $\mathrm{AD}$ use (overall and for the two most commonly used chemical subgroups). Even after adjusting for sex, age, family income, self-assessment of health, and number of medical consultations, the overall consumption of $\mathrm{AD}$ and SSRI was significantly higher in the 2012 cohort. However, no significant difference was observed in the consumption of TCA between the two cohorts. Considering that $\mathrm{AD}$ use differed between older males and females, a trend analysis was conducted to evaluate medication use stratified by sex. However, the results obtained within each stratum did not differ from those observed in the total population.

\section{DISCUSSION}

This study identified a significant increase in $\mathrm{AD}$ use between 1997 and 2012, primarily due to increased consumption of SSRI. In both cohorts and in all age groups, consumption of $\mathrm{AD}$ was higher among females. In the 2012 cohort, in addition to females, increased age and income, self-assessment of health as reasonable, and attending five or more medical consultations in the past 12 months were positively associated with $\mathrm{AD}$ use.

Between 1997 and 2012, the consumption of AD by older adults from Bambuí significantly increased approximately three fold, regardless of the characteristics associated with their use in this cohort. Growth in the consumption of $\mathrm{AD}$ has also been observed in higher-income countries among the general adult ${ }^{2,17}$ and older adult population. ${ }^{4,8,12,13}$ A Brazilian population-based study showed a significant increase in $\mathrm{AD}$ use from $8.4 \%$ to $31.6 \%$ but included not only the older groups but all residents aged $\geq 15$ years. ${ }^{20}$

Previous studies have elucidated the reasons for the growing $\mathrm{AD}$ use, and these reasons are not mutually exclusive. The most obvious reason is the increased prevalence of depression in the older population. ${ }^{1}$ In fact, in addition to improved diagnosis of depressive disorders by healthcare professionals, ${ }^{2,20}$ depression in the final stage of life is a common event among older adults owing to the presence of chronic diseases, impaired functional capacity, loneliness, and decreased social support network. ${ }^{1,13}$ Another cause would be extended drug treatment for depression, particularly among those with a history of multiple depressive episodes. This has also been observed in international studies, whether based on primary data $^{14,21,22}$ or on databases of consultations and medical prescriptions. ${ }^{18} \mathrm{~A}$ third cause is growing acceptance among healthcare professionals and patients of the new generation of AD such as SSRI, which have fewer side effects and are better tolerated and safer than TCA and MAOI (older class), particularly in overdose situations. ${ }^{14}$ The fact that depressive older adults are commonly treated with drugs at the expense of other therapeutic options, such as psychotherapy, also should not be discarded. ${ }^{24}$ 
Table 1. Comparison of the profile of the 1997 cohort (baseline) and survivors (2012 cohort) in Bambuí, state of Minas Gerais, Southeastern Brazil.

\begin{tabular}{|c|c|c|c|}
\hline Variable & $1997(N=351)$ & $2012(N=462)$ & $\mathrm{p}$ \\
\hline Age in years ${ }^{\mathrm{a}}$ & $79.8(3.7)$ & $79.9(3.8)$ & 0.712 \\
\hline \multicolumn{4}{|l|}{ Sex } \\
\hline Male & 39.9 & 33.6 & \\
\hline Female & 60.1 & 66.5 & 0.063 \\
\hline \multicolumn{4}{|l|}{ Education (years completed) } \\
\hline 0 & 39.0 & 24.7 & \\
\hline 1 to 3 & 29.6 & 36.6 & \\
\hline$\geq 4$ & 31.4 & 38.7 & $<0.001$ \\
\hline \multicolumn{4}{|l|}{ Marital status } \\
\hline Married/Consensual union & 36.5 & 33.4 & \\
\hline Widowed & 50.4 & 57.7 & \\
\hline Single or divorced & 13.1 & 8.9 & 0.056 \\
\hline \multicolumn{4}{|c|}{ Family income (in minimum wage equivalents) } \\
\hline$<2.0$ & 35.1 & 20.9 & \\
\hline 2.0 to 3.9 & 34.3 & 44.6 & \\
\hline$\geq 4.0$ & 30.6 & 34.6 & $<0.001$ \\
\hline \multicolumn{4}{|l|}{ Lives alone } \\
\hline No & 80.1 & 73.3 & \\
\hline Yes & 19.9 & 26.7 & 0.025 \\
\hline \multicolumn{4}{|l|}{ Depressive disorders } \\
\hline No & 57.2 & 80.7 & \\
\hline Yes & 42.8 & 19.3 & $<0.001$ \\
\hline \multicolumn{4}{|l|}{ Self-assessment of health } \\
\hline Very good/Good & 31.9 & 53.5 & \\
\hline Reasonable & 45.9 & 37.5 & \\
\hline Poor & 22.2 & 9.1 & $<0.001$ \\
\hline \multicolumn{4}{|l|}{ Number of chronic diseases } \\
\hline 0 & 35.0 & 14.2 & \\
\hline 1 & 43.0 & 46.4 & \\
\hline$\geq 2$ & 22.0 & 39.4 & $<0.001$ \\
\hline \multicolumn{4}{|c|}{ Inability to perform at least one basic activity of daily living } \\
\hline No & 75.6 & 85.0 & \\
\hline Yes & 24.4 & 15.0 & 0.001 \\
\hline \multicolumn{4}{|c|}{ Number of medical consultations in the last 12 months } \\
\hline 0 to 1 & 33.1 & 23.8 & \\
\hline 2 to 4 & 40.2 & 46.3 & \\
\hline$\geq 5$ & 26.8 & 29.9 & 0.014 \\
\hline \multicolumn{4}{|c|}{ Hospitalization history in the past 12 months } \\
\hline No & 71.8 & 77.9 & \\
\hline Yes & 28.2 & 22.2 & 0.048 \\
\hline \multicolumn{4}{|l|}{ Health insurance coverage } \\
\hline No & 82.6 & 66.6 & \\
\hline Yes & 17.4 & 34.4 & $<0.001$ \\
\hline
\end{tabular}

a Mean (SD). 


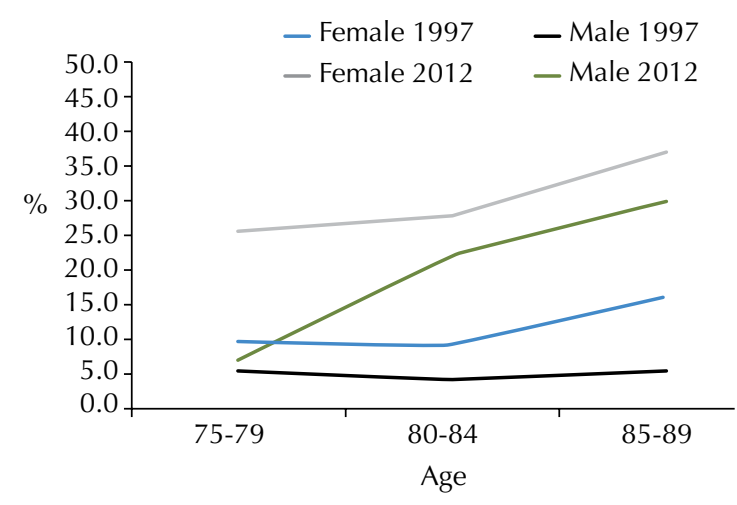

$\overline{\text { Figure. Antidepressant use by sex and age among individuals }}$ aged 75-89 years. Bambuí, MG, Southeastern Brazil, 1997 and 2012.

In line with the results of international population-based studies, ${ }^{2,17,25}$ the increased consumption of AD in Bambuí was primarily due to the increased use of SSRI, considering that the consumption of TCA was similar between the two cohorts. The prevalence of SSRI among AD used by the 2012 cohort is consistent with that observed in Brazil ${ }^{6,19}$ and other countries. ${ }^{22}$ This result indicates the possibility that among the older people of Bambuí, increased consumption of $\mathrm{AD}$ results from greater acceptance of SSRI by professionals and patients. After the appearance of this chemical subgroup, general practitioners have more frequently prescribed $\mathrm{AD}$, a practice that used to be restricted to psychiatrists. ${ }^{17}$ It is noteworthy that only $1.0 \%$ of the population consulted a psychiatrist. Furthermore, a negative correlation was observed between the increased prevalence of AD consumption and depression in the 2012 cohort. This may be due to adequate treatment among older adults in the 2012 cohort, resulting in improvement or remission of depressive symptoms and consequently a negative rating for the GHQ-12. This may also be a consequence of $\mathrm{AD}$ use in the management of other health problems, such as anxiety disorders and other chronic diseases. ${ }^{4}$

The identification of independent factors associated with AD use was largely confined to the 2012 cohort. In the 1997 cohort, the only characteristic associated with $\mathrm{AD}$ use after multiple adjustments was the number of medical consultations.

The consumption of $\mathrm{AD}$ was higher among females. International ${ }^{12,14,17,25}$ and Brazilian studies ${ }^{6,10,19}$ have shown an association between females and $\mathrm{AD}$ use. Some authors argue that the higher consumption of $\mathrm{AD}$ among females is due to the increased prevalence of depressive disorders in this group. ${ }^{6,10,17}$ However, in the present study, the association between females and $\mathrm{AD}$ use remained significant regardless of the presence of depressive disorders. Grunenbaum ${ }^{12}$ (2008) draws attention to the possibility of feminization of depression, because females identify psychiatric conditions and pursue treatment for these disorders more intensely than males. In this study, the consumption of AD did not significantly differ between males and females presenting with depressive disorders, but was significantly different among those without depressive disorders (data not shown). This result could indicate that, in Bambuí, older females use $\mathrm{AD}$ to treat health problems other than depression, such as anxiety disorders, sleep disturbances, physical problems, and even social problems caused by the difficulties experienced in daily life. ${ }^{25}$ Alternatively, females may adhere to the pharmacological treatment of depression more often than males.

Other sociodemographic characteristics associated with $\mathrm{AD}$ use were increased age and higher income. A positive association between age and $\mathrm{AD}$ use was observed in other older groups. ${ }^{13,25}$ General practitioners have reported depression at the end of life as a spectrum that includes loneliness, lack of social network, and impaired functionality. ${ }^{13} \mathrm{As}$ for the positive association between income and $\mathrm{AD}$ use, increased access to medications could be due to greater ability to bear health costs among those with better socioeconomic status. ${ }^{10}$ In Bambuí, the prevalence of depressive disorders was higher among the lower income strata (data not shown), which raises concerns about possible inequalities in mental health care in this population segment due to its limited access to mental health care services. ${ }^{6}$

In the case of descriptive variables related to health conditions and use of health care services, only the self-assessment of health (in the first case) and the number of medical consultations (in the second) were associated with $\mathrm{AD}$ use after adjusting for other covariables. The positive association between consumption of $\mathrm{AD}$ and worse self-assessment of health (even restricted to assessment as "reasonable") is consistent with results observed among older Australian adult ${ }^{25}$ and indicates the importance of subjective assessment of health in determining $\mathrm{AD}$ use. The positive association between consumption of $\mathrm{AD}$ and the number of medical consultations is related to the need for a prescription from a medical professional in order to obtain the drug.

One limitation of this study is the inability to assess the appropriate $\mathrm{AD}$ use with regard to drug indication and dosage, owing to the lack of use of a gold standard method for diagnosing depression as well as the unavailability of data on duration of use/dosage for medications and access to psychotherapy. The GHQ- $12^{11}$ screening tool used to evaluate common mental disorders in the study population showed the same accuracy as the 30-item Geriatric Depression Scale (GDS-30) in diagnosing depressive symptoms. ${ }^{7}$ However, the GHQ-12 only verifies the presence of symptoms of depression and does not define clinical diagnosis. Moreover, the cutoff value used to classify the participants as positive did not allow differentiation 
Table 2. Results of univariate and multivariate analyses of factors associated with antidepressant use among individuals aged 75-89 years. Bambuí, MG, Southeastern Brazil, 2012.

\begin{tabular}{|c|c|c|c|c|c|}
\hline Characteristics & $\%$ & $\mathrm{PR}_{\mathrm{raw}}$ & $95 \% \mathrm{Cl}$ & PR adjusted & $95 \% \mathrm{Cl}$ \\
\hline Age & $80.7(4.0)^{\mathrm{a}}$ & 1.06 & $1.01 ; 1.10$ & 1.05 & $1.01 ; 1.09$ \\
\hline \multicolumn{6}{|l|}{ Sex } \\
\hline Male & 14.8 & 1.00 & & 1.00 & \\
\hline Female & 28.0 & 1.89 & $1.24 ; 2.87$ & 1.77 & $1.11 ; 2.82$ \\
\hline \multicolumn{6}{|l|}{ Education (years completed) } \\
\hline None & 19.3 & 1.00 & & 1.00 & \\
\hline 1 to 3 & 29.4 & 1.29 & $0.81 ; 2.04$ & 1.43 & $0.87 ; 2.35$ \\
\hline$\geq 4$ & 25.1 & 1.30 & $0.83 ; 2.05$ & 1.33 & $0.78 ; 2.26$ \\
\hline \multicolumn{6}{|l|}{ Marital status } \\
\hline Married/Consensual union & 19.5 & 1.00 & & 1.00 & \\
\hline Widowed & 26.7 & 1.37 & $0.94 ; 2.00$ & 1.02 & $0.66 ; 1.58$ \\
\hline Single or divorced & 19.5 & 2.00 & $0.50 ; 2.02$ & 1.02 & $0.53 ; 1.97$ \\
\hline \multicolumn{6}{|c|}{ Family income (in minimum wages) } \\
\hline$<2.0$ & 18.2 & 1.00 & & 1.00 & \\
\hline 2.0 to 3.9 & 20.0 & 1.07 & $0.65 ; 1.76$ & 1.40 & $0.82 ; 2.39$ \\
\hline$\geq 4.0$ & 30.2 & 1.61 & $1.00 ; 2.60$ & 1.93 & $1.08 ; 3.45$ \\
\hline \multicolumn{6}{|l|}{ Lives alone } \\
\hline No & 23.0 & 1.00 & & 1.00 & \\
\hline Yes & 23.8 & 1.03 & $0.71 ; 1.50$ & 1.33 & $0.82 ; 2.13$ \\
\hline \multicolumn{6}{|l|}{ Depressive disorders } \\
\hline No & 20.9 & 1.00 & & 1.00 & \\
\hline Yes & 34.8 & 1.67 & $1.18 ; 2.36$ & 1.26 & $0.86 ; 1.86$ \\
\hline \multicolumn{6}{|l|}{ Self-assessment of health } \\
\hline Very good/Good & 18.2 & 1.00 & & 1.00 & \\
\hline Reasonable & 29.5 & 1.62 & $1.14 ; 2.30$ & 1.62 & $1.13 ; 2.32$ \\
\hline Poor & 31.0 & 1.70 & $1.01 ; 2.87$ & 1.50 & $0.83 ; 2.70$ \\
\hline \multicolumn{6}{|l|}{ Number of chronic diseases } \\
\hline None & 24.6 & 1.00 & & 1.00 & \\
\hline 1 & 24.1 & 0.98 & $0.60 ; 1.59$ & 0.80 & $0.50 ; 1.26$ \\
\hline$\geq 2$ & 23.3 & 0.95 & $0.57 ; 1.57$ & 0.74 & $0.45 ; 1.22$ \\
\hline \multicolumn{6}{|c|}{ Inability to perform at least one basic activity of daily living } \\
\hline No & 22.1 & 1.00 & & 1.00 & \\
\hline Yes & 31.9 & 1.45 & $0.98 ; 2.14$ & 1.01 & $0.65 ; 1.59$ \\
\hline \multicolumn{6}{|c|}{ Number of medical consultations } \\
\hline 0 to 1 & 12.7 & 1.00 & & 1.00 & \\
\hline 2 to 4 & 23.8 & 1.87 & $1.09 ; 3.23$ & 1.61 & $0.92 ; 2.82$ \\
\hline$\geq 5$ & 31.9 & 2.51 & $1.45 ; 4.33$ & 2.10 & $1.16 ; 3.81$ \\
\hline \multicolumn{6}{|l|}{ Hospitalization history } \\
\hline No & 22.0 & 1.00 & & 1.00 & \\
\hline Yes & 27.7 & 1.26 & $0.87 ; 1.83$ & 1.07 & $0.69 ; 1.64$ \\
\hline \multicolumn{6}{|l|}{ Health insurance coverage } \\
\hline No & 20.0 & 1.00 & & 1.00 & \\
\hline Yes & 31.4 & 1.57 & $1.13 ; 2.17$ & 1.37 & $0.95 ; 1.97$ \\
\hline
\end{tabular}


Table 3. Antidepressant use among older adults aged 75-89 years. Bambuí, MG, Southeastern Brazil, 1997 and 2012.

\begin{tabular}{lcccccc}
\hline Antidepressant use & 1997 & 2012 & $\mathrm{PR}_{\text {raw }}$ & $95 \% \mathrm{Cl}$ & $\mathrm{PR}_{\text {adjusted }} \mathrm{a}^{\mathrm{a}}$ & $95 \% \mathrm{Cl}$ \\
\hline Global (\%) & 8.3 & 23.6 & 2.86 & $1.94 ; 4.20$ & 2.87 & $1.94 ; 4.25$ \\
Tricyclic compounds (\%) & 5.7 & 5.6 & 0.99 & $0.56 ; 1.74$ & 0.89 & $0.49 ; 1.62$ \\
Selective serotonin reuptake & 2.3 & 17.3 & 7.60 & $3.62 ; 15.05$ & 7.50 & $3.74 ; 15.02$ \\
inhibitors (\%) & & & & & & \\
\hline
\end{tabular}

Estimation of PR using Poisson regression with robust variance.

${ }^{a}$ Adjusted for sex, age, family income, self-rated health assessment, and number of medical consultations.

between mild or severe symptoms. For the first case, psychotherapy is indicated, whereas drug therapy is the first choice in cases of severe depression. ${ }^{9}$ Another limitation is the impossibility of verifying whether $\mathrm{AD}$ was prescribed by a psychiatrist. The present results cannot be generalized to other older groups, particularly those attending geriatric day hospitals or nursing homes. However, the study has advantages, particularly when compared with studies on drug dispensing or those based on prescriptions because it uses data on drug use. In addition, the accuracy of the measurements was ensured by the verification of drug label and prescription. The populationbased strategy adopted, the minimum loss of information on the medications used by the eligible participants, and uniform procedures for data collection between the cohorts ensured the reliability and internal validity of the study. Furthermore, to the best of our knowledge, this is

\section{REFERENCES}

1. Atlantis E, Sullivan T, Sartorius N, Almeida OP. Changes in the prevalence of psychological distress and use of antidepressants or anti-anxiety medications associated with comorbid chronic diseases in the adult Australian population, 2001-2008. Aust N Z J Psychiatry. 2012;46(5):445-56. DOI: $10.1177 / 0004867411433218$

2. Barbui C, Campomori A, D'Avanzo B, Negri E, Garattini $\mathrm{S}$. Antidepressant drug use in Italy since the introduction of SSRIs: national trends, regional differences and impact on suicide rates. Soc Psychiatry Psychiatr Epidemiol. 1999;34(3):152-6. DOI:10.1007/s001270050127

3. Barbui C, Broglio E, Laia AC, D'Agostino S, Enrico F, Ferraro L, et al. Cross-sectional Database Analysis of Antidepressant Prescribing in Italy. J Clin Psychopharmacol. 2003;23(1):31-4. DOI:10.1097/00004714-200302000-00006

4. Blazer DG, Hybels CF, Fillenbaum GG, Pieper CF. Predictors of antidepressant use among older adults: have they changed over time? Am J Psychiatry. 2005;162(4):705-10. DOI:10.1176/appi.ajp.162.4.705

5. Boing AF, Melo GR, Boing AC, Moretti-Pires RO, Peres KG, Peres MA. Associação entre depressão e doenças crônicas: um estudo populacional. Rev Saude Publica. 2012;46(4):617-23. DOI:10.1590/S0034-89102012005000044

6. Brunoni AR, Nunes MA, Figueiredo R, Barreto SM, Fonseca MJM, Lotufo PA, et al. Patterns of benzodiazepine and antidepressant use among middle- the first Brazilian population-based study that evaluated the trends in $\mathrm{AD}$ consumption among older adults.

In summary, the increased consumption of $\mathrm{AD}$ and the predominance of new generation drugs were consistent with findings observed in international studies of different populations and experimental designs. The positive association observed between $\mathrm{AD}$ consumption and income may indicate potential inequalities in accessing mental health services. Further studies employing different methodologies and designs (e.g., qualitative and longitudinal epidemiological studies) are necessary to deepen knowledge concerning AD use among older people. Furthermore, it can support interventions that will improve access to pharmaceutical care services with coverage and quality that are adequate for managing health problems of psychological origin in this population segment. aged adults: the Brazilian longitudinal study of adult health (ELSA-Brasil). J Affect Disord. 2013;151(1):71-7. DOI:10.1016/j.jad.2013.05.054

7. Costa E, Barreto SM, Uchoa E, Firmo JOA, LimaCosta MF, Prince M. Is the GDS-30 better than the GHQ-12 for screening depression in elderly people in the community? The Bambuí Health Aging Study (BHAS). Int Psychogeriatr. 2006;18(3):493-503. DOI:10.1017/S1041610205002954

8. Desplenter F, Caenen C, Meelberghs J, Hartikainen S, Sulkava R, Bell JS. Change in psychotropic drug use among community-dwelling people aged 75 years and older in Finland: repeated cross-sectional population studies. Int Psychogeriatr. 2011;23(8):1278-84. DOI: $10.1017 / \mathrm{S} 1041610211000718$

9. Fleck MP, Berlim MT, Lafer B, Sougey EB, Del Porto JA, Brasil MA, et al. Revisão das diretrizes da Associação Médica Brasileira para o tratamento da depressão (Versão integral). Rev Bras Psiquiatr. 2009;31Suppl 1:7-17. DOI:10.1590/S1516-44462009000500003

10. Garcias CMM, Pinheiro RT, Garcias GL, Horta BL, Brum CB. Prevalence of antidepressant use and associated factors among adults in Pelotas, Rio Grande do Sul State, Brazil, 2006. Cad Saude Publica. 2008;24(7):1565-71. DOI:10.1590/S0102-311X2008000700011

11. Goldberg DP, Hillier VF. A scaled version of the General Health Questionnaire. Psychol Med. 1979;9(1):139-45. DOI:10.1017/S0033291700021644 
12. Grunenbaum MF, Oquendo MA, Manly JJ. Depressive symptoms and antidepressant use in a random community sample of ethnically diverse, urban elder persons. J Affect Disord. 2008;105(1-3):273-7. DOI:10.1016/j.jad.2007.04.022

13. Hansen DG, Rosholm JU, Gichangi A, Vach W. Increased use of antidepressants at the end of life: population-based study among people aged 65 years and above. Age Ageing. 2007;36(4):449-54. DOI:10.1093/ageing/afm056

14. Harris T, Carey IM, Shah SM, DeWilde S, Cook DG. Antidepressant prescribing in older primary care patients in community and care home settings in England and Wales. J Am Med Dir Assoc. 2012;13(1):41-7. DOI:10.1016/j.jamda.2010.09.005

15. Lieberman JA. History of the Use of Antidepressants in Primary Care. J Clin Psychiatry. 2003;5 Suppl 7:6-10.

16. Lima-Costa MF, Firmo JOA, Uchoa E. The Bambuí Cohort Study of Aging: methodology and health profile of participants at baseline. Cad Saude Publica. 2011;27Suppl 3:327-35. DOI:10.1590/S0102-311X2011001500002

17. Middleton N, Gunnell D, Whitley E, Dorling D, Frankel F. Secular trends in antidepressant prescribing in the UK, 1975-1998. J Public Health Med. 2001;3(4):262-7. DOI:10.1093/pubmed/23.4.262

18. Moore M, Yuen HM, Dunn N, Mullee MA, Maskell J, Kendrick T. Explaining the rise in antidepressant prescribing: a descriptive study using the general practice research database. BMJ. 2009;339:b3999. DOI:10.1136/bmj.b3999

19. Quintana MI, Andreoli SB, Moreira FG, Ribeiro WS, Feijo MM, Bressan RA, et al. Epidemiology of psychotropic drug use in Rio de Janeiro, Brazil: gaps in mental illness treatments. PLoS ONE. 2013;8(5):e62270. DOI:10.1371/journal.pone.0062270

20. Rodrigues MAP, Facchini LA, Lima MS. Modificações nos padrões de consumo de psicofármacos em localidade do Sul do Brasil. Rev Saude Publica. 2006;40(1):107-14. DOI:10.1590/S0034-89102006000100017

21. Sihvo S, Wahlbeck K, McCallum A, Sevon T, Arffman M, Haukka J, et al. Increase in the duration of antidepressant treatment from 1994 to 2003: a nationwide population-based study from Finland. Pharmacoepidemiol Drug Saf. 2010;19(11):1186-93. DOI:10.1002/pds.2017

22. Soudry A, Dufouil C, Ritchie K, Dartigues JF, Tzourio C, Alpérovitch A. Factors associated with antidepressant use in depressed and non-depressed communitydwelling elderly: the three-city study. Int / Geriatr Psychiatry. 2008;23(3):324-30. DOI:10.1002/gps.1890

23. Ufer M, Meyer SM, Junge O, Selke G, Volz HP, Hedderich J, et al. Patterns and prevalence of antidepressant drug use in the German state of Baden-Wuerttemberg: a prescription-based analysis. Pharmacoepidemiol Drug Saf. 2007;16(10):1153-60. DOI:10.1002/pds.1405

24. Unützer J, Katon W, Callahan CM, Williams Jr JW, Hunkeler E, Harpole L, et al. Depressed treatment in an sample of 1,801 depressed old adults in primary care. J Am Geriatr Soc. 2003;51(4):505-14. DOI:10.1046/j.1532-5415.2003.51159.x

25. Zhang Y, Chow V, Vitry Al, Ryan P, Roughead EE, Caughey GE, et al. Antidepressant use and depressive symptomatology among older people from the Australian Longitudinal Study of Ageing. Int Psychogeriatr. 2010;22(3):437-44. DOI:10.1017/S1041610209991554

Research supported by the Fundação Amparo à Pesquisa de Minas Gerais (FAPEMIG - Case APQ-00526-1), the Centro Nacional de Desenvolvimento Científico e Tecnológico (CNPq - Case 482721/2011-1), and the National Postdoctoral Program in Health (SUS 101/2009 - research grant to Castro-Costa E). Firmo JOA and Peixoto SV are recipients of CNPq productivity scholarships. Presented at the "IX Brazilian Congress of Epidemiology" (EPIVIX), Vitória, Espírito Santo, in 2014.

The authors declare no conflict of interest. 